\title{
Effects of Calcium Antagonists, Felodipine and Nicardipine, on Cerebral Circulation in Dogs
}

\author{
Motoharu TANAKA, Yutaka YOSHIDA*, Akio MITOMI, \\ Mikio NAKAZAWA and Shoichi IMAI \\ Department of Pharmacology. Niigata University School of Medicine. \\ 757 Asahimachi-dori 1. Niigata 951. Japan
}

Accepted October 13, 1989

\begin{abstract}
The effects of a calcium antagonist of the dihydropyridine type. felodipıne, on the cerebral circulation were studied in comparison with those of nicardipine in pancuronium-bromide immobilized unanesthetized dogs. Felodipine $(0.3-10 \mathrm{~kg} /$ $\mathrm{kg}$. i.v.) and nicardipine $(0.3-10 \mu \mathrm{kg} / \mathrm{kg}$, i.v.) produced a dose-related decrease in mean blood pressure with almost equal potencies. However, at a dose of $3 \mu \mathrm{g} / \mathrm{kg}$, felodipine produced a more prominent increase in cerebral blood flow (CBF) than nicardipine. Decreases in cerebral vascular resistance were significantly greater in the felodipine group at doses of 0.3 and $3 \mu \mathrm{g} / \mathrm{kg}$. when compared with the nicardipine group. Cerebral oxygen consumption calculated by multiplying the arterio-venous difference of oxygen content by CBF was increased by these two drugs, but the changes were minimal. These data suggest that the increase in CBF produced by felodipine and nicardipine was primarily due to the direct dilatation of the cerebral blood vessels.
\end{abstract}

Felodipine, ethylmethyl 4-(2,3-dichloro phenyl) - 1,4 - dihydro-2,6-dimethyl-3,5-pyridinedicarboxylate, (Fig. 1) is a derivative of dihydropyridine that dilates peripheral vessels (1) and coronary arteries (2) significantly, and it is thought to be useful for the treatment of hypertension and angina pectoris.

In recent vears, calcium antagonists of the dihydropyridine type such as nicardipine (3. 4) and nimodipine $(5,6)$ were found to be effective for the treatment of cerebral ischemia or the cerebral vasospasm secondary to the subarachnoid hemorrhage.

Although it was already reported that felodipine increases the cerebral blood flow in SHR (7) and renal hypertensive rabbits (8) using the microsphere distribution method, precise analysis was not done yet. In the present study, we have examined the effect of felodipine on the cerebral blood flow in relation to the effects on the cerebral oxygen<smiles>CCOC(=O)C1=C(C)NC(C)=C(C(=O)OCC)C1c1cccc(Cl)c1Cl</smiles>

Felodipine<smiles>CC(=O)OC(=O)C1=C(C)NC(C)=C(C(=O)OCCN(C)Cc2ccc(Cl)cc2)C1c1cccc([N+](=O)[O-])c1</smiles>

Nicardipine hydrochloride

Fig. 1. Chemical structures of felodipine and nicardipine hydrochloride.

* To whom all correspondence should be addressed. 
consumption and the systemic hemodynamics using immobilized unanesthetized dogs. For comparison, the effects of nicardipine were also studied.

\section{Materials and Methods}

Mongrel dogs of either sex, weighing 8-11 $\mathrm{kg}$. were anesthetized with sodium thiopental (30 $\mathrm{mg} / \mathrm{kg}$, i.v.), and an endotracheal tube was inserted into the trachea. Anesthesia was maintained by artificial ventilation with 1\% halothane. Arterial blood pressure was monitored by a pressure transducer (Statham $P-50)$ connected to the catheter introduced into the right femoral artery. Heart rate was counted continuously with a cardiac tachometer (San-ei $477 \mathrm{~B}$ ) triggered by aortic pressure pulses. The $\mathrm{pH}, \mathrm{P}_{\mathrm{O}_{2}}$ and $\mathrm{P}_{\mathrm{CO}_{2}}$ of the arterial blood drawn from the right axillary artery via polyethylene catheter were measured by a blood gas analyzer (Radiometer Blood Microsystem BMS3MK2) and maintained around 7.3-7.4, above $100 \mathrm{mmHg}$ and $30-40 \mathrm{mmHg}$, respectively, by adjusting the ventilation rate and the tidal volume.

Measurement of the cerebral blood flow was conducted following the methods of Michenfelder et al. (9) and Chin et al. (10) (venous outflow method). Briefly, the head of the dog was fixed by ear bars in an upright position, the sagital sinus was exposed by a midline frontal-occipital incision, and a craniotomy was performed using a dental drill (Beaver-Labo. Osaka Electric). To exclude contamination from the extracranial circulation, bilateral incision of the frontaloccipital bone was made by the dental drill, and the bone edges were packed with bone wax (Lukens Bone Wax 900) to occlude the diploic vein. The sagital sinus was cannulated with a tapered polyethylene cannula. The blood outflow from the sinus was measured by an electromagnetic flowmeter (Statham SP 2201) and drained into the jugular vein. The blood flow (CBF) was calculated using the following formula:

$$
C B F=\frac{C V F}{B W \times 0.43} \times 100 \quad(\mathrm{mi} / 100 \mathrm{~g} / \mathrm{min})
$$

CVF: cerebral venous outflow $(\mathrm{ml} / \mathrm{min}$ )

BW: brain weight $(g)$

The cerebral vascular resistance was calcul- ated dividing the mean arterial blood pressure by the cerebral blood flow. To measure the arterio-venous difference $\left(\mathrm{A}-\mathrm{VO}_{2}\right)$ of the blood oxygen content, the arterial blood from the femoral artery and the venous blood from the sagital sinus were diverted to an arteriovenous oxygen difference recorder (A-Vox System) distal to the flow probe at a constant rate of $7 \mathrm{ml} / \mathrm{min}$ by a roller pump (LKB Multiperpex 2115). The cerebral oxygen consumption $\left(\mathrm{CMRO}_{2}\right)$ was calculated on the basis of Fick's principle using the following formula:

$$
\begin{aligned}
& \mathrm{CMRO}_{2}=\frac{\mathrm{CBF} \times \mathrm{A}-\mathrm{VO}_{2} \text { difference }}{100} \\
& \text { ( } \mathrm{ml} / 100 \mathrm{~g} / \mathrm{min} \text { ) }
\end{aligned}
$$

Before cannulation of the sagital sinus. dogs were heparinized intravenously with $500 \mathrm{U} / \mathrm{kg}$ of heparin and a further $100 \mathrm{U} / \mathrm{kg}$ was added every hour thereafter. After completion of the operation, halothane anesthesia was stopped, and the animals were ventilated artificially by air. To immobilize the animal. $0.08 \mathrm{mg} / \mathrm{kg}$ of pancuronium-bromide (Mioblock Injection, Organon) was injected every hour intravenously. After the experiments, the animals were put to death under anesthesia, and the brain was taken out and weighed. Drugs were administered intravenously in a step-wise fashion after almost complete recovery of each parameter to the pre-drug values (after about $15 \mathrm{~min}$ ).

Statistical analysis: All values are expressed as the mean \pm S.E.M. Values obtained after treatment were compared with the pre-drug values by means of Student's paired $t$-test. and the differences between the groups were compared by means of Student's unpaired $t$ test. $P$ values less than 0.05 were regarded as significant.

Drugs: Felodipine (synthesized at Hässle) was dissolved at first in a small amount of ethanol. After addition of polvethylene glycol 400 , the solution was adjusted to $45 \%$ polyethylene glycol 400 by adding distilled water. Nicardipine hydrochloride (Yamanouchi Pharmaceutical Co.) was dissolved with $45 \%$ polyethylene glycol 400 solution. Both of them were diluted with $45 \%$ polyethylene glycol to the desired concentrations for administration. Administration of the solvent 
alone did not produce any change in any hemodynamic parameter.

\section{Results}

In this experiment, dogs whose CBF increased more than $70 \%$ by $8 \% \mathrm{CO}_{2}$ inhalation were used to investigate the effects of drugs on CBF to avoid the contamination with the extracerebral blood. All the parameters monitord just before the drug administration are shown in Table 1. Significant differences were not observed in any parameter between the felodipine and the nicardipine groups, and the $\mathrm{CO}_{2}$ responses were not different in both groups $(342.8 \pm 38.8 \%$ for the felodipine and $301.8 \pm 40.8 \%$ for the nicardipine group).

The time courses of the changes in heart rate (HR), mean blood pressure (MBP) and cerebral blood flow (CBF) induced by felodipine $(0.3-10 \mu \mathrm{g} / \mathrm{kg}$. i.v.) and nicardipine $(0.3-10 \mu \mathrm{g} / \mathrm{kg}$, i.v.) are shown in Fig. 2. Data were expressed as percent changes from the pre-drug values. Felodipine did not change HR significantly at a dose range of $0.3-3 \mu \mathrm{g} / \mathrm{kg}$, but a significant decrease was observed $1 \mathrm{~min}$ after the administration of 10 $\mu \mathrm{g} / \mathrm{kg}$. Nicardipine $(3 \mu \mathrm{g} / \mathrm{kg})$ decreased HR slightly at $1-2 \mathrm{~min}$ (about $2 \%$ ). Felodipine lowered MBP dose-dependently at a dose range of $0.3-10 \mu \mathrm{g} / \mathrm{kg}$. At a dose of $1 \mu \mathrm{g} / \mathrm{kg}$, the maximal decrease in MBP $(-7.0 \%)$ was observed $1 \mathrm{~min}$ after the administration. while the maximal decreases $(-12.9 \%$ and $-2.4 .1 \%$, respectively) were observed at 2 $\min$ at doses of 3 and $10 \mu \mathrm{g} / \mathrm{kg}$. Nicardipine produced a dose-dependent decrease in MBP at a dose range of $0.3-10 \mu \mathrm{g} / \mathrm{kg}$. The minimum value was attained $1 \mathrm{~min}$ after the administration. The hypotensive efficacies of these two drugs seem to be almost equal. Felodipine increased CBF dose-dependently at a range of $0.3-3 \mu \mathrm{g} / \mathrm{kg}$. The maximum value was attained at $1 \mathrm{~min}$. The maximum increase in CBF (32.2\%) was observed at a dose of $3 \mu \mathrm{g} / \mathrm{kg}$. The maximum increase in CBF observed at $5 \mathrm{~min}$ at a dose of $10 \mu \mathrm{g} / \mathrm{kg}$ was smaller than that observed at $1 \mathrm{~min}$ with $3 \mu \mathrm{g} / \mathrm{kg}$. Nicardipine produced a dose-related increase in CBF in a dose range of $0.3-10$ $\mu \mathrm{g} / \mathrm{kg} ; 3$ and $10 \mu \mathrm{g} / \mathrm{kg}$ of nicardipine maximally increased CBF by $9.5 \%$ (at $2 \mathrm{~min}$ ) and $25.5 \%$ (at $0.5 \mathrm{~min}$ ), respectively. The felodipine-induced increase in CBF was more prominent than the nicardipine-induced one at a dose range of $0.3-3 \mu \mathrm{g} / \mathrm{kg}$.

Figure 3 depicts the dose-effect relationship of the maximal decrease in MBP induced by felodipine and nicardipine. Both of the drugs lowered MBP in a dose-related manner, and the efficacies are almost equal to each other at the dose range of $0.3-10 \mu \mathrm{g} / \mathrm{kg}$. The times required to reach the minimum were not significantly different between the drugs in any dose. As shown in Fig. 4, felodipine and nicardipine induced the increases in CBF which were associated with decreases in CVR. The times required to reach the maximal level of CBF were not different significantly

Table 1. Initial values of the experimental parameters in pancuronium-bromide immobilized unanesthetized dogs

\begin{tabular}{|c|c|c|c|}
\hline \multirow[b]{2}{*}{ Parameters } & \multicolumn{2}{|c|}{ Pre-drug values } & - \\
\hline & $\begin{array}{l}\text { Felodipine } \\
\text { group }(n=6)\end{array}$ & $\begin{array}{l}\text { Nicardipine } \\
\text { group }(n=6)\end{array}$ & $P$ value \\
\hline HR (keats!min) & $159 \pm 16$ & $194 \pm 10$ & N.S. \\
\hline $\operatorname{MBP}(\mathrm{mm} H \mathrm{~g})$ & $101.3 \pm 5.8$ & $111.2 \pm 15.4$ & N.S. \\
\hline $\mathrm{CBF}(\mathrm{ml}, 100 \mathrm{~g} \cdot \mathrm{min})$ & $57.6 \pm 13.8$ & $43.5 \pm 3.2$ & N.S. \\
\hline CVR $(\mathrm{mmHg} \cdot 100 \mathrm{~g} \cdot \mathrm{min} / \mathrm{ml})$ & $2.18 \pm 0.41$ & $2.82 \pm 0.31$ & N.S. \\
\hline $\mathrm{CMRO}_{2}(\mathrm{ml} / 100 \mathrm{~g} \cdot \mathrm{min})$ & $4.90 \pm 1.19$ & $3.54 \pm 0.15$ & N.S. \\
\hline $\mathrm{Po}_{2}(\mathrm{mmHg})$ & $131 \pm 9$ & $133 \pm 10$ & N.S. \\
\hline $\mathrm{PCO}_{2}(\mathrm{mmHg})$ & $32.8 \pm 1.2$ & $31.8 \pm 1.0$ & N.S. \\
\hline pH & $7.34 \pm 0.01$ & $7.34 \pm 0.02$ & N.S. \\
\hline
\end{tabular}

Heart rate (HR), mean blood pressure (MBP), cerebral blood flow (CBF), cerebral vascular resistance (CVR). cerebral oxygen consumption $\left(\mathrm{CMRO}_{2}\right)$, artertal blood contents of oxygen $\left(\mathrm{Po}_{2}\right)$ and carbon dioxide $\left(\mathrm{PCO}_{2}\right)$ and $\mathrm{pH}$. Each value represents the mean \pm S. E.M. of 6 experiments. 
Felodipine

Nicardipine
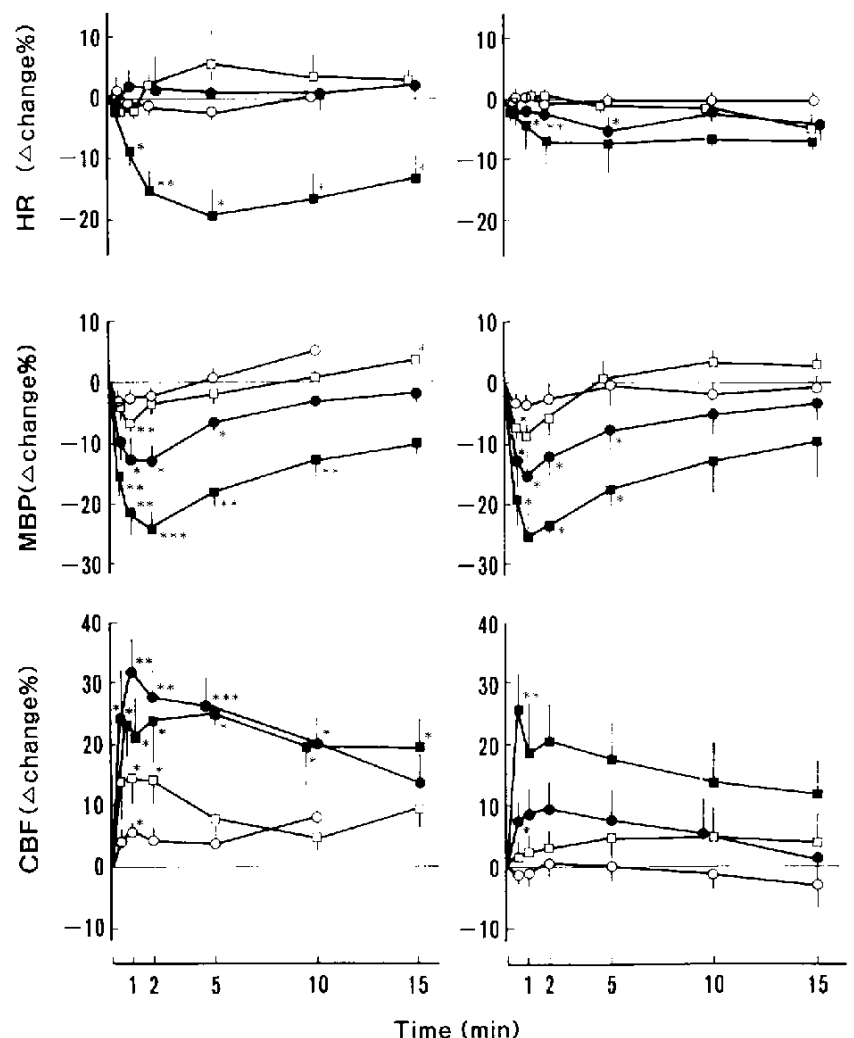

Fig. 2. Time courses of changes in the heart rate (HR), mean arterial blood pressure (MBP), cerebrat blood flow (CBF) after administration of $0.3(-\mathrm{O}-), 1(-\square-), 3(-\mathbf{O}-), 10(-\mathbf{\square}-) \mu \mathrm{g} / \mathrm{kg}$, i.v. of felodipine and nicardipine in mongrel dogs. ${ }^{*} \mathrm{P}<0.05{ }^{* *} \mathrm{P}<0.01$ and ${ }^{* * *} \mathrm{P}<0.001$, when compared with predrug values. Each value indicates the mean \pm S.E.M. of 6 experiments, except for the value obtained with $3 \mu \mathrm{g} / \mathrm{kg}$ of felodipine. which represents the mean $\pm S$.E.M. of 5 experiments.

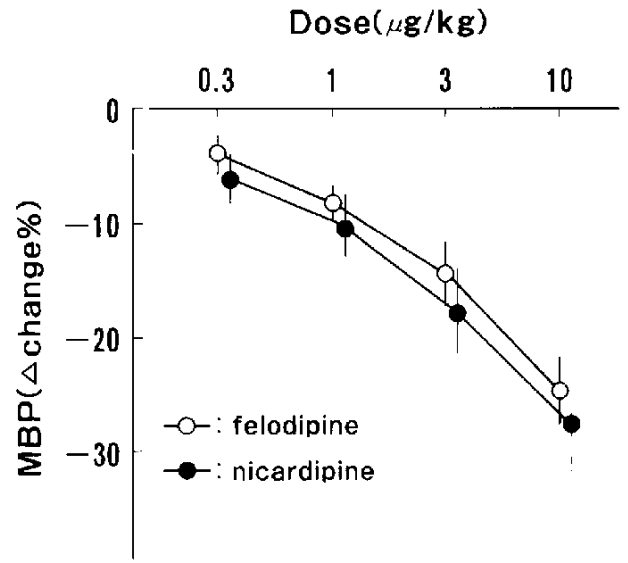

Fig. 3. Maximum response in mean blood pressure (MBP) after $0.3-10 \mu \mathrm{g} / \mathrm{kg}$. i.v.-administration of felodipine (-O-) and nicardipine (-O-) in mongrel dogs. Each value indicates the mean $\pm S$.E.M. of 6 experimerits, except for the value obtained with $3 \mu \mathrm{g} / \mathrm{kg}$ of felodipine, which represents the mean \pm S.E.M. of 5 experiments. 


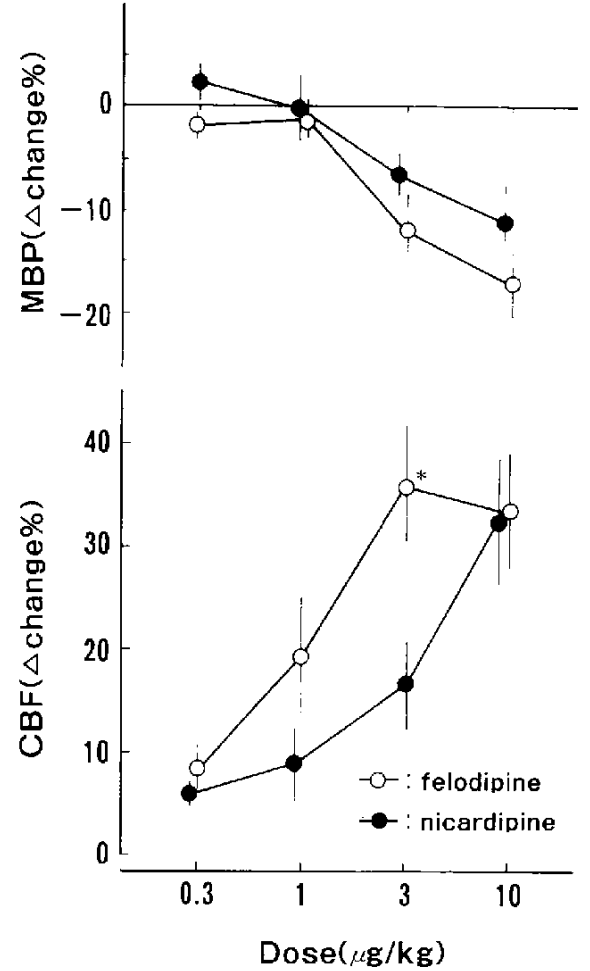

Fig. 4. Maximum responses in cerebral blood flow (CBF) and concomitant changes in mean blood pressure (MBP) after $0.3-10 \% \mathrm{~g} / \mathrm{kg}$, i.v.-administration of felodipine (-O-) and nicardipine (-O-) in mongrel dogs. "P<0.05. compared with the nicardipine group. Each value indicates the mean \pm S.E.M. of 6 experiments, except for the value obtained with $3 \mu \mathrm{g} / \mathrm{kg}$ of felodipine. Which represents the meantS.E.M. of 5 experiments.

between the felodipine and the nicardipine groups at any dose. Felodipine produced a more prominent increase in CBF than nicardipine at a dose of $3 \mu \mathrm{g} / \mathrm{kg}(36.0 \%$ and $16.4 \%$. respectively).

The decrease in CVR produced by felodipine was significantly greater when compared with that by nicardipine at doses of $0.3 \mu \mathrm{g} / \mathrm{kg}$ $(-9.7 \%$ and $-3.3 \%$, respectively) and $3 \mu \mathrm{g} / \mathrm{kg}$ ( $-33.7 \%$ and $-19.0 \%$, respectively) (Fig. 5 ).

The relationship between the percent change in CBF and the percent change in $\mathrm{CMRO}_{2}$ is shown in Fig. 6. Although $\mathrm{CMRO}_{2}$ was increased by these drugs, the regression lines depart far from $y=x$ at any dose, being $y=3.83 x$ for felodipine and $y=2.70 x$ for

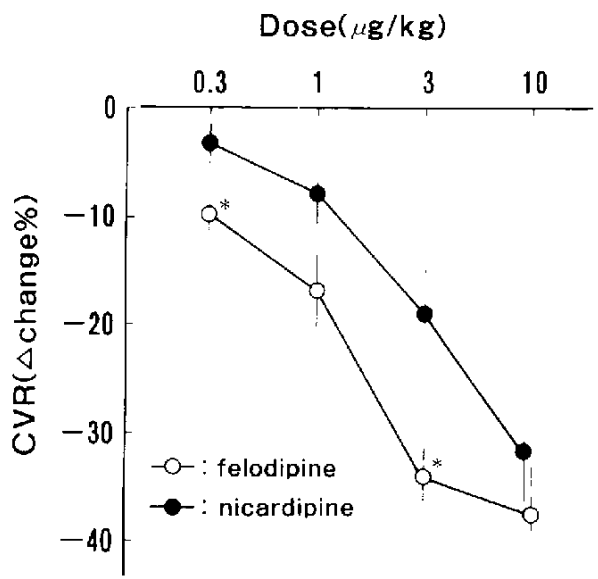

Fig. 5. Dose response curves of the changes in cerebral vascular resistance (CVR) at the time of maximum increase in cerebral blood flow by $0.3-10$ $\mu \mathrm{g} / \mathrm{kg}$. i.v.-administration of felodipine (-O--) and nicardipine (- -) in mongrel dogs. * $P<0.05$. compared with the nicardipine group. Each value indicates the mean \pm S.E.M. of 6 experiments, except for the value obtained with $3 \mu \mathrm{g} / \mathrm{kg}$ of felodipine, which represents the mean \pm S.E.M. of 5 experiments.

nicardipine. The gradients of these lines are not significantly different from each other.

\section{Discussion}

The effects of felodipine on the cerebral blood flow have already been studied in the spontaneously hypertensive rat (7) and in the renal hypertensive rabbit (8). However, in these studies, the cerebral blood flow was measured with the microsphere method, and the effects on the cerebral oxygen consumption were not evaluated. To analyze the effects of drugs on the cerebral blood flow in relation to those on the cerebral oxygen consumption, we used the dog and measured the cerebral blood flow with a venous outflow method. This is the only method with which the cerebral blood flow with virtually no contamination with the blood from the extracerebral circulation could be measured in the dog together with the cerebral oxygen consumption with a minimal surgical disruption of the normal cerebrovascular anatomy. To further ascertain that only the blood from the brain was led out, we used dogs whose cerebral venous outflow increased more than $70 \%$ by $\mathrm{CO}_{2}$ inhalation (there existed no dif- 

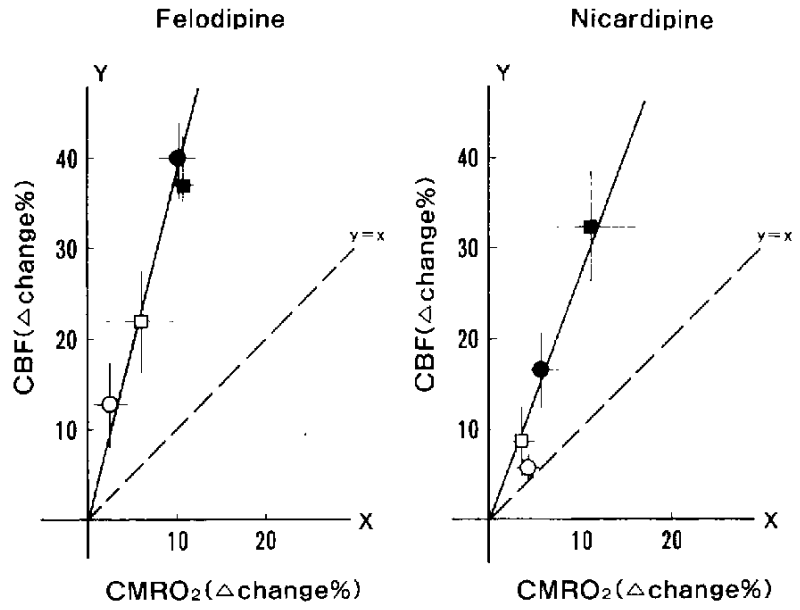

Fig. 6. Relationship between the maximum changes in cerebral blood flow (CBF) and the coricornitant changes in cerebral oxvgen collsumption $\left(\mathrm{CMRO}_{2}\right)$ after $0.3(-\mathrm{O}-), 1(-\square-), 3(-\mathrm{O}-), 10(-\square-)$ $\mu \mathrm{g} / \mathrm{kg}$. i.v.-administration of felodipine and nicardipine in mongrel dogs. Each value indicates the mean \pm S.E.M. of 6 experimerts, except for the value obtained with $3 \mu \mathrm{g} / \mathrm{kg}$ of felodipine, which represents the mean $\pm S . E . M$. of 5 experiments.

ference in the reactivity to $\mathrm{CO}_{2}$ between the felodipine- and the nicardipine groups). The sagital sinus outflow measured with this method represents about $43 \%$ of the total brain circulation area $(9,10)$.

The increase in cerebral blood flow was observed with doses of felodipine about $1 / 3$ of those used in the hypertensive rabbits (8) and less than 1/10 of those used in the SHR (7). This may be due to the species differences and/or the state of the animals.

Felodipine produced a prominent increase in CBF associated with a decrease in CVR that was greater than that produced by nicardipine at doses of $0.3-3 \mu \mathrm{g} / \mathrm{kg}$, while the decreases in MBP produced by these two substances were almost the same. The increase in cerebral blood flow produced by $10 \mu \mathrm{g} / \mathrm{kg}$ of felodipine was smaller than that produced by $3 \mu \mathrm{g} / \mathrm{kg}$ of this compound. As the cerebral vascular resistance was further decreased with this dose, the smaller increase in flow may be ascribed to the profound fall of the blood pressure and the marked decrease in heart rate produced with this dose. These data suggest a higher selectivity of felodipine on the cerebral vessels as compared with nicardipine Pearce and Bevan (11) pointed out that the low selectivity of diltiazem on the cerebral vasculature might be ascribed to its low hydrophobicity. The high selectivity of nimodipine was explained by Haws et al. (12) on the basis of its high hydrophobicity. The higher selectivity of felodipine on the cerebral blood vessels as compared with that of nicardipine could be explained by the higher hydrophobicity of the former. Although both these two compounds are more soluble in organic solvents than in water, the organic solvent/ water solubility ratios are much higher with the former than with the latter (data not shown).

The cerebral oxygen consumption $\left(\mathrm{CMRO}_{2}\right)$ calculated by multiplying the A$\mathrm{VO}_{2}$ difference by CBF was increased after administration of felodipine and nicardipine. The increases were observed at 5 or $10 \mathrm{~min}$ after administration when CBF reached a steady plateau level, indicating the enhancement of the cerebral metabolism by these two drugs. This is in accordance with the results of experiments conducted by d'Avella et al. (13) in unanesthetized rats with nimodipine, another dihydropyridine calcium antagonist. Although Haws et al. (12) and Mohamed et al. (14) reported that nimodipine did not increase $\mathrm{CMRO}_{2}$ or cerebral glucose uptake. their experiments were conducted in an- 
esthetized animals. As a possible explanation for the enhancement of the cerebral metabolic rates, the elevation of cyclic AMP level due to inhibition of phosphodiesterase $(15,16)$ could be invoked, for it was known that intracarotid administration of cyclic AMP or intracisternal dibutyryl cyclic AMP could increase $\mathrm{CBF}, \mathrm{CMRO}_{2}$ and cerebral glucose consumption and reduce CVR in the baboon (17). The part of the increase in CBF produced by felodipine and nicardipine may be explained by the enhanced $\mathrm{CMRO}_{2}$. However. the percent increases in $\mathrm{CMRO}_{2}$ produced by felodipine and nicardipine were much smaller than those in CBF, indicating that the increase in CBF produced by these drugs was mainly due to a direct vasodilating action on the cerebral blood vessels; if a substance increases CBF through enhancement of the cerebral oxygen consumption, the percent increase in CBF would be equal to the percent increase in cerebral oxygen consumption $(10,14)$.

\section{References}

1 Ljung, B.: Vascular selectivity of felodipine. Drugs 29, Supp. 2, 46-58 (1985)

2 Verdouw, P.D., Wolffenbuttel, B.H.R. and Scheffer, M.G.: Cardiovascular actions of the calmodulin inhibitor felodipine. Arch. Pharmacol. 323, 350-354 (1983)

3 Takenaka, T. and Handa, J.: Cerebrovascular effects of YC-93, a new vasodilator, in dogs, monkeys and human patients. Int. J. Clin. Pharmacol. Biopharm. 17. 1-11 (1979)

4 Handa, J., Yoneda, S., Koyama, T., Matsuda, M. and Handa, H.: Experimental cerebral vasospasm in cats: Modification by a new synthetic vasodilator YC-93. Surg. Neurol. 3, 195-199 (1975)

5 Tanaka, K., Gotoh, F., Muramatsu, F., Fukuuchi, Y., Amano, T., Okayasu, H. and Suzuki, N.: Effects of nimodipine (Bay e 9736) on cerebral circulation in cats. Arzneimittelforschung 30, 1494-1497 (1980)

6 Gelmers, H.J.: Effects of calcium antagonists on the cerebral circulation. Am. J. Cardiol. 59,
173B-176B (1987)

7 Nordlander, N.: Hernodynamic effects of short and long term administration of felodipine in spontaneously hypertensive rats. Drugs 29, Supp. 2, 90-101 (1985)

8 Bolt, G.R. and Saxena, P.R.: Acute systemic and regional hemodynamic effects of felodipine. a new calcium antagonist, in conscious renal hypertensive rabbits. J. Cardiovasc. Pharmacol. 6, 707-712 (1984)

9 Michenfelder, J.D., Messick, J.M. and Theye, R.A.: Simultaneous cerebral blood flow measured by direct and indirect methods. J. Surg. Res. 8 , 475-481 (1968)

10 Chin, W.-P., Imai, S., Nakano, U., Takeda, K., Tamatsu, $H$. and Ushijima, T.: Effects of drugs on the cerebral circulation of the dog in relation to the oxygen consumption. Br. J. Pharmacol. 79, 897-906 (1983)

11 Pearce, W.J. and Bevan, J.A.: Diltiazem and autoregulation of canine cerebral blood flow. J. Pharmacol. Exp. Ther. 242, 812-817 (1987)

12 Haws, C.W., Gourley, J.K. and Heistad, D.D.: Effects of nimodipine on cerebral blood flow. J. Pharmacol. Exp. Ther. 225, 24-28 (1982)

13 d'Avella, D., Cicciarello, R., Torre, F.L., Pinci, P., Greenberg, R.P., d'Aquino, S. and Caputi, A.P.: The effect of the calcium antagonist nimodipine upon local cerebral glucose utilization in the rat brain. Life Sci. 34, 2583-2588 (1984)

14 Mohamed, A.A., Mendelow, A.D., Teasdale, G.M., Harper, A.M. and McCulloch, J.: Effect of the calcium antagonist nimodipine on local cerebral blood flow and metabolic coupling. J. Cereb. Blood Flow Metab. 5, 26-33 (1985)

15 Epstein, P.M., Fiss, K., Hachisu, R. and Andrenyak, D.M.: Interaction of calcium antagonists with cyclic AMP phosphodiesterases and calmodulin. Biochem. Biophys. Res. Commun. 105, 1142-1149 (1982)

16 Norman, J.A., Ansell, J. and Phillipps, M.A.: Dihydropyridine $\mathrm{Ca}^{2+}$ entry blockers selectively inhibit peak I CAMP phosphodiesterase. Eur. J. Pharmacol. 93, 107-112 (1983)

17 Tagashira, Y., Matsuda, M., We!ch, K.M.A., Chabi, E. and Meyer, J.S.: Effects of cyclic AMP and dibutyryl cyclic AMP on cerebral hemodynamics and metabolism in the baboon. J Neurasurg. 46, 484-493 (1977) 